\title{
EFFECT OF INTRATHECAL ROPIVACAINE WITH DEXMEDETOMIDINE FOR OPERATIVE AND POST OPERATIVE ANALGESIA: A PROSPECTIVE RANDOMIZED STUDY
}

Nitish Kumar Parmar ${ }^{1}$, Geeta Bhandari², K. S. Shahi' ${ }^{3}$, Gyan Chand ${ }^{4}$, Dolly Rani ${ }^{5}$, Garima Sharma ${ }^{6}$, Santhosh Kumar ${ }^{7}$

\section{HOW TO CITE THIS ARTICLE:}

Nitish Kumar Parmar, Geeta Bhandari, K. S. Shahi, Gyan Chand, Dolly Rani, Garima Sharma, Santhosh Kumar. "Effect of Intrathecal Ropivacaine with Dexmedetomidine for Operative and Post-Operative Analgesia: A Prospective Randomized Study". Journal of Evolution of Medical and Dental Sciences 2014; Vol. 3, Issue 11, March 17; Page: 2917-2925, DOI: 10.14260/jemds/2014/2225

ABSTRACT BACKGROUND: This prospective randomized double blind study was conducted to evaluate the effect and safety of intrathecal dexmedetomidine added to isobaric ropivacaine. MATERIALS AND METHODS: 120 adult female patients, who underwent vaginal hysterectomies, were randomly allocated to receive intrathecally either $3 \mathrm{ml}$ of $0.75 \%$ isobaric ropivacaine $+0.5 \mathrm{ml}$ normal saline (Group R) or $3 \mathrm{ml}$ of $0.75 \%$ isobaric ropivacaine $+5 \mu \mathrm{g}$ dexmedetomidine in $0.5 \mathrm{ml}$ of normal saline (Group D). Following intrathecal administration, duration of onset of sensory and motor blockade, maximum dermatomal level achieved, duration of analgesia, hemodynamic parameters and incidence of side effects were observed. RESULTS: Duration of onset of sensory block upto T10, T8 and the highest level of block achieved i. e. T6 were similar in both the groups. The mean time of sensory regression to S2 was $297.71 \pm 34.11$ min in group D and $221.35 \pm 22.70$ min in group R. Time to achieve Bromage score 0 was significantly slower with the addition of dexmedetomidine $(229.37 \pm 28.74 \mathrm{~min}$ in group R vs. $258.55 \pm 30.46 \mathrm{~min}$ in group D). Duration of postoperative analgesia was significantly greater in group D $(270.00 \pm 38.75 \mathrm{~min})$ as compared to group R (174.77 $\pm 22.31 \mathrm{~min})$. The maximum VAS score for pain was less in group D (4.42 \pm 0.69$)$ as compared to group $\mathrm{R}(7.03 \pm 0.78)$. There were no significant difference in hemodynamic parameters and incidence of side effects in both the groups. CONCLUSION: The addition of dexmedetomidine to ropivacaine intrathecally produces significantly longer sensory and motor blockade along with better postoperative analgesia, and excellent hemodynamic stability without any significant side effects. KEYWORDS: Dexmedetomidine, Ropivacaine, Intrathecal, Hysterectomy.

INTRODUCTION: Spinal anaesthesia is a an established mode of anaesthesia for lower abdominal surgeries because it blunts the "stress response" to surgery, decreases intraoperative blood loss and lowers the incidence of postoperative thromboembolic events. ${ }^{1-3}$ Bupivacaine is the most commonly used local anesthetic for neuraxial anaesthesia, however it is associated with cardiotoxic side effects. ${ }^{4}$ As a result, an enantiomer-specific amide type local anesthetic, ropivacaine, which has lower potential for cardiac and central nervous systemic toxicity and shows greater differentiation between sensory and motor blockade along with improved hemodynamic stability was introduced in 1996 and approved for spinal anesthesia in the European Union in 2004.5

Various adjuvants have been used intrathecally to improve the quality and duration of the spinal anaesthesia along with better postoperative analgesia. The most commonly used agents have been opioids, such as morphine, fentanyl and sufentanil. However addition of opioids has been associated with undesirable side effects like respiratory depression, pruritis, nausea and vomiting. 
Various other drugs like and other drugs such as clonidine, magnesium sulfate, neostigmine, ketamine and midazolam, have also been used but none is without associated adverse effects.6,7 Dexmedetomidine, is a novel and highly selective alpha-2 adrenoceptor agonist, having antinociceptive action for both somatic and visceral pain. ${ }^{8}$ Various studies have reported the efficacy and safety of intrathecal dexmedetomidine in combination with bupivacaine.9-11 However very little data is available on usage of dexmedetomidine in spinal anaesthesia with ropivacaine. Therefore this study was planned to study the synergistic effect and safety between dexmedetomidine and isobaric ropivacaine in spinal anesthesia and compare this with isobaric ropivacaine alone in the patients undergoing vaginal hysterectomy.

MATERIALS AND METHODS: After getting institutional ethics committee approval this prospective randomised double blind study was conducted on 120 patients aged between 18-65 years with ASA grade I or II, undergoing vaginal hysterectomy under spinal anesthesia. Patients, who refused for spinal anesthesia, were ASA grade III \& IV, age less than 18 years or greater than 65 years were excluded from the study. Patients with known history of head injury, psychiatric diseases, weight more $70 \mathrm{~kg}$, height less than $145 \mathrm{~cm}$, patients with a known history of intake of beta blocker's, alpha2 adrenergic receptor antagonists, calcium channel blockers, ACE inhibitors, patients with known history of allergy to any test drugs, patients suffering from major hepatic, renal or cardiovascular system dysfunction, contraindications to spinal anesthesia or any patient who has received any analgesic drugs within the past 24 hours were also exclude from the study.

After a well informed consent and thorough pre-anesthetic evaluation, all patients were cannulated in the preoperative room. In operating room they were preloaded with $15 \mathrm{ml} / \mathrm{kg}$ of lactated Ringer's solution and noninvasive blood pressure (NIBP), pulse oximeter, electrocardiogram (ECG) were attached to all patients. Lumber puncture was performed in $\mathrm{L}_{3}-\mathrm{L}_{4}$ or $\mathrm{L}_{4}-\mathrm{L}_{5}$ intervertebral space in sitting position through a midline approach using 25G Quincke's needle under all aseptic precautions. Patients were randomized on the basis of sealed envelope technique to receive one of the following drug (drug was made by an anesthesiologist blinded to the study protocol).

GROUP R: $3 \mathrm{ml}$ volume of $0.75 \%$ isobaric ropivacaine $(22.5 \mathrm{mg})$ and $0.5 \mathrm{ml}$ of normal saline.

Group D: $3 \mathrm{ml}$ volume of $0.75 \%$ isobaric ropivacaine $(22.5 \mathrm{mg}$ ) with $5 \mu \mathrm{g}$ dexmedetomidine in $0.5 \mathrm{ml}$ of normal saline.

The drug was injected intrathecally over approximately 10 to 15 seconds. Immediately after intrathecal injection, patient was then made to lie in supine position. The Anesthesiologist performing the block was blinded to the study drug and intraoperative vitals were recorded. The level of sensory block was checked by loss of pinprick sensation by 23 G hypodermic needle and dermatomal levels were tested every 2 minutes until the highest required level was stabilized for four consecutive tests. Testing was then conducted every 10 minutes until the time of two segment regression of block. Further testing was performed every 20 minutes intervals until the recovery to $\mathrm{S}_{2}$ dermatome. 
Simultaneously motor block was evaluated using the Bromage Scale as follows:

BROMAGE 0 - The patient is able to move the hip, knee and ankle.

BROMAGE 1 - The patient is unable to move the hip, but is able to move the knee and ankle.

BROMAGE 2 - The patient is unable to move the hip, and knee, but is able to move the ankle.

BROMAGE 3 - The patient is unable to move the hip, knee, and ankle.

Hemodynamic parameters were recorded every 3 minutes after spinal administration of selected drug for first 15 minutes and subsequently every 5 minutes for half an hour after spinal anesthesia then at every 10 minutes till the end of surgery. Any fall in BP below $100 \mathrm{~mm} \mathrm{Hg}$ or more than $20 \%$ of base line was treated with administration of oxygen, fast iv fluids and vasopressor (mephentermine 3 to $6 \mathrm{mg}$ iv) as needed. Any fall in heart rate less than 60 beats or more than $20 \%$ of base line was treated with injection atropine $0.3 \mathrm{mg}$ increments iv, as needed. Data regarding the highest dermatomal level of sensory blockade, the time to reach this level from the time of spinal injection, time to $S_{2}$ sensory regression were recorded. All durations were calculated considering the time of spinal injection as time zero. After commencement of surgery, patient's anxiety and sedation level was evaluated by Modified Ramsay Sedation Score as follows-

\section{Modified Ramsay Sedation score is as below:}

1. Patient is anxious, agitated or restless.

2. Patient is co-operative, oriented and tranquil alert.

3. Patient responds to Commands.

4. Asleep, but brisk response to light glabellar tap or loud auditory stimulus.

5. Sluggish response to light glabellar tap or loud auditory stimulus.

6. No response.

The incidence of adverse effects such as nausea, vomiting, shivering, itching, pruritus, respiratory depression, sedation and hypotension were recorded. Postoperatively, pain scores was recorded by using Visual Analogue pain scale (VAS) between $0-10(0=$ no pain, $10=$ the most severe pain), initially every 1 hour for 2 hours, every 2 hours for next 8 hours and then after every 4 hours till 24 hours. Injection tramadol in the dose of $2 \mathrm{mg}$ per $\mathrm{kg}$ IV (max 100mg) was given as rescue analgesia when VAS $\geq 4$. All data was analysed using IBM SPSS Statistics 21.0 software. The qualitative data between two groups was compared using Chi Square test and for comparison of the continuous variable independent t- test was used. $\mathrm{P}<0.05$ was considered statistically significant. Power of study was 80 at $95 \%$ confidence interval.

RESULTS: Initially 120 patients were included in the study. All the patients achieved adequate level of anesthesia except one patient in each group. Both patients required general anesthesia because of inadequate sensory blockade so these patients were excluded from the study. Finally 59 patients in Group $\mathrm{R}$ and 59 patients in Group D were included in the statistical analysis. The groups were comparable with respect to demographic characteristics (Table 1). The results regarding the characteristics of sensory as well as motor block are summarized in (Table 2). Block regression was significantly slower with the addition of intrathecal dexmedetomidine (Group D) as compared to ropivacaine alone (Group R). Both, time to two segment regressions and time to S2 regression were significantly more with 
intrathecal dexmedetomidine. On statistical analysis, the maximum VAS score in the group D was lower as compared to group $\mathrm{R}$ up to 24 hours postoperatively (Table 3 ). The duration of analgesia was also significantly prolonged with the addition of dexmedetomidine as compared to ropivacaine alone $(270.00 \pm 38.75 \mathrm{~min}$ and $174.77 \pm 22.31 \mathrm{~min}$, respectively). There were no serious adverse effects in the study patients. Only 3 patients in group $\mathrm{R}$ and 2 patients in group $\mathrm{D}$ had hypotension which required treatment with a single dose of $6 \mathrm{mg}$ mephentermine, while none of the patients in both groups suffered from nausea, vomiting, sedation and bradycardia.

DISCUSSION: In this study we have tried to evaluate the efficacy and safety of intrathecal dexmedetomidine in combination with ropivacaine. $\alpha_{2}$ adrenoceptor agonist like clonidine has been extensively used in anaesthetic practice for their sympatholytic, sedative, analgesic, and anestheticsparing effects. ${ }^{12,13}$ Dexmedetomidine is a highly selective $\alpha_{2}$ agonist with a 10 times greater $\alpha 2 / \alpha 1$ selectivity than clonidine $\alpha_{1}$ receptors. ${ }^{12-14}$ Dexmedetomidine has most commonly been used for ICU sedation, however there is a growing body of evidence which supports its use as an adjuvant to local anaesthetic agents in neuraxial blocks.

Al-Ghanem et $\mathrm{al}^{9}$ and Al-Mustafa et al ${ }^{10}$ in their studies observed that the effect of dexmedetomidine is dose dependent and that the onset of sensory blockade was more rapid with the use of dexmedetomidine. However in our study we observed that addition of dexmedetomidine did not enhance the speed of onset of sensorimotor blockade. This can be attributed to the fact that the above authors added dexmedetomidine to bupivacaine as compared to ropivacaine in our study.

In a study conducted by Kanazi et al ${ }^{15}$ they observed that $3 \mu \mathrm{g}$ dexmedetomidine or $30 \mu \mathrm{g}$ clonidine added to $13 \mathrm{mg}$ spinal bupivacaine equally prolonged the duration of sensory and motor block with minimal side-effects in urologic surgical patients. Similar findings were observed in our study where we observed that there was a significant prolongation in duration of both sensory as well motor blockade in the group receiving intrathecal dexmedetomidine along with ropivacaine. Similar sensory block characteristics were found by Gupta et al. ${ }^{16}$ In another study conducted by Gupta et $\mathrm{al}^{11}$ they observed that the total duration of motor blockade was prolonged in dexmedetomidine group as compared to fentanyl group $(421 \pm 21 \mathrm{~min}$ vs. $149.3 \pm 18.2 \mathrm{~min}, \mathrm{P}$ value $<0.0001)$.

The mechanism of action by which intrathecal alfa- 2 adrenoceptor agonist prolong the motor and sensory block of local anaesthetics is not well known. The local anaesthetics act by blocking sodium channels, whereas the alfa-2 adrenoceptor agonist acts by binding to pre-synaptic C-fibres and post-synaptic dorsal horn neurons. The analgesic action of intrathecal alfa-2 adrenoceptor agonist is by depressing the release of C-fibre transmitters and by hyperpolarisation of post-synaptic dorsal horn neurons. ${ }^{17}$ It may be an additive or synergistic effect secondary to the different mechanism of action of the local anaesthetic and the alfa- 2 adrenoceptor agonist as studied by Salgado et al. ${ }^{18}$ This antinociceptive effect may explain the prolongation of sensory block when added to spinal anaesthetics. The prolongation of the motor block of spinal anaesthetics may result from the binding of alfa- 2 adrenoceptor agonists to motor neurons in the dorsal horn. ${ }^{19,} 20$

In a dose-finding study by Khaw et al21, different doses $(10,15,20$ and $25 \mathrm{mg})$ of ropivacaine were evaluated (after dilution to a total volume of $3 \mathrm{ml}$ with normal saline) in caesarean section. The effective dose (ED50 and ED95) for spinal ropivacaine was calculated to be $16.7 \mathrm{mg}$ (ED50) and 26.8 $\mathrm{mg}$ (ED95). In a study by Kessler et $\mathrm{al}^{22}$, the authors concluded that isobaric ropivacaine $(22.5 \mathrm{mg})$ 
was suitable for spinal anesthesia for lower abdominal gynaecological surgery. Various studies have reported that $5 \mu \mathrm{g}$ intrathecal dexmedetomidine is safe and devoid of any neurotoxic side effect, hence, we used $5 \mu \mathrm{g}$ dexmedetomidine along with $22.5 \mathrm{mg}$ isobaric Ropivacaine $(0.75 \%) .{ }^{9}, 10,15$

There was a significant reduction delay in the time to fist rescue analgesia in group receiving intrathecal dexmedetomidine. Also there was a significant reduction in the analgesic consumption and the highest VAS score recorded in the first 24 hours. Similar findings are observed by Mahendru et al ${ }^{23}$, Gupta et $\mathrm{al}^{16}$ and Al-Mustafa et al. ${ }^{10}$

Talke et $\mathrm{al}^{24}$, observed in their study that $\alpha-2$ adrenergic agents also have anti-shivering property. In our study shivering was noted in 3 patients in Group R and in one patient in Group D. This is in agreement with the above mentioned study. The combination of ropivacaine and dexmedetomidine provided excellent hemodynamic stability. We also did not observe any hemodynamic side effect in our study. Bradycardia, hypotension and sedation which are the most dreaded side effects of alpha adrenoceptors agonist were also not observed in our study which can be attributed to the usage of low dose of dexmedetomidine. Our study adds to the growing body of evidence that dexmedetomidine can be effectively and safely used as an intrathecal adjunct to ropivacaine however our study was limited by its small sample size and larger randomized controlled studies are recommended to firmly establish the efficacy and safety of intrathecal dexmedetomidine.

To conclude our study reveals that $22.5 \mathrm{mg}$ of isobaric ropivacaine ( $3 \mathrm{ml}$ of $0.75 \%$ ) when administered intrathecally along with $5 \mu \mathrm{g}$ dexmedetomidine for lower abdominal surgery it provides significantly longer sensory and motor blockade, better postoperative analgesia, reduced requirement of rescue analgesic in first 24 hour and excellent haemodynamic stability with minimal side effects.

\section{REFERENCES:}

1. Kehlet $\mathrm{H}$. The stress response to surgery: Release mechanisms and the modifying effects of pain relief. Acta Chir Scand Suppl 1988; 550: 22.

2. Rodgers A, Walker N, Schug S, McKee A, Kehlet H, van Zundert A, et al. Reduction of postoperative mortality and morbidity with epidural or spinal anaesthesia: results from overview of randomised trials. BMJ 2000; 321:1493.

3. Urwin SC, Parker MJ, Griffiths R. General versus regional anaesthesia for hip fracture surgery: a meta-analysis of randomized trials. Br J Anaesth 2000; 84(4): 45.

4. Graf BM. The cardiotoxicity of local anesthetics: the place of ropivacaine. Curr Top Med Chem 2001; 1(3): 207-14.

5. Marret E, Thevenin A, Gentili M, Bonnet F. Comparison of intrathecal bupivacaine and ropivacaine with different doses of sufetanil. Acta Anaesthesiol Scand 2011; 55: 670-6.

6. Shukla D, Verma A, Agarwal A, Pandey H. D, Tyagi C. Comparative study of intrathecal Dexmedetomidine with intrathecal Magnesium sulfate used as adjuvants to Bupivacaine. J Anaesthesiol Clin Pharmacol 2011; 27(4): 495-9.

7. Schug SA, Saunders D, Kurowski I, Paech MJ. Neuraxial drug administration: a review of treatment options for anaesthesia and analgesia. CNS Drugs 2006; 20(11): 917-33.

8. Kalso EA, Poyhia R, Rosenberg PH. Spinal antinociception by dexmeditomidene a highly selective alpha-2 adrenergic agonist. Pharmacol Toxicol 1991; 68: 140-3. 
9. Al Ghanem SM, Massad IM, Al-Mustafa MM, Al-Zaben KR, Qudaisat IY, Qatawneh AM, et al. Effect of adding dexmedetomidine versus fentanyl to intrathecal bupivacaine on spinal block characteristics in gynecological procedures: A double blind controlled study. Am J Appl Sci 2009; 6: 882-7.

10. Al-Mustafa MM, Abu-Halaweh SA, Aloweidi AS, Murshidi MM, Ammari BA, Awwad ZM, et al. Effect of dexmedetomidine added to spinal bupivacaine for urological procedures. Saudi Med J 2009; 30: 365-70.

11. Gupta R, Verma R, Bogra J, Kohli M, Raman R, Kushwaha JK. A Comparative study of intrathecal dexmedetomidine and fentanyl as adjuvants to Bupivacaine. J Anaesthesiol Clin Pharmacol 2011; 27: 339-43.

12. Hennawy AME, Abd-Elwahab AM, Abd-Elmaksoud AM, El-Ozairy HS and Boulis S R. Addition of clonidine or dexmedetomidine to bupivacaine prolongs caudal analgesia in children. $\mathrm{Br} \mathrm{J}$ Anaesth 2009; 103(2): 268-74.

13. Ebert TJ, Hall JE, Barney JA, Uhrich TD, Colinco MD. The effects of increasing plasma concentrations of dexmedetomidine in humans. Anesthesiology 2000; 93: 382-94.

14. Virtanen R, Savola J-M, Saano V, Nyman L. Characterization of the selectivity, specificity and potency of medetomidine as an $\alpha 2$-adrenoceptor agonist. Eur J Pharmacol 1988;150: 9-14.

15. Kanazi GE, Aouad MT, Jabbour-Khoury SI, AI Jazzar MD, Alameddine MM, AI-Yaman R, et al. Effect of low dose dexmedetomidine or clonidine on the characteristics of bupivacaine spinal block. Acta Anaesthesiol Scand 2006; 50(2): 222-7.

16. Gupta R, Bogra J, Verma R, Kohli M, Kushwaha JK, Kumar S. Dexmedetomidine as an intrathecal adjuvant for postoperative analgesia. Indian J Anaesth 2011; 55: 347-51.

17. Eisanach GC, De Kock M, Klimscha W. Alfa-2 adrenergic agonist for regional anaesthesia. Anaesthesiology 1996; 85: 655-74.

18. Salgado PF, Sabbag AT, Silva PC, Brienze SL, Dalto HP, Modolo NS, et al. Synergistic effect between dexmedetomidine and $0.75 \%$ ropivacaine in epidural anesthesia. Rev Assoc Med Bras 2008; 54(2): 110-5.

19. Harada Y, Nishioka K, Collins JG. Visceral antinociceptive effects of spinal clonidine combined with morphine, enkephalin, or U50, 488H. Anaesthesiology 1995; 83: 344-52.

20. Yaksh TL, Reddy SV. Studies in primate on the analgesic effects associated with intrathecal actions of opiates, adrenergic agonists and baclofen. Anesthesiology 1981; 54: 451-67.

21. Khaw K., Ngan Kee W., Wong E., Liu J., Chung R. Spinal ropivacaine for cesarean section. A dosefinding study. Anesthesiology 2001; 95: 1346-1350,

22. Kessler P., Eichler A., Wilke H., Strouhal U., Bremerich D. Intrathecal ropivacaine versus bupivacaine for lower abdominal gynaecological procedures. Eur. J. Anaesth 2001; 18, 86, Abs A304.

23. Mahendru V, Tewari A, Katyal S, Grewal A, Singh M R, Katyal R: A comparison of intrathecal dexmedetomidine, clonidine, and fentanyl as adjuvants to hyperbaric bupivacaine for lower limb surgery: A double blind controlled study. J Anaesthesiol Clin Pharmacol 2013; 29: 496-502.

24. Talke P, Tayefeh F, Sessler DI, Jeffrey R, Noursalehi M, Richardson C: Dexmedetomidine does not alter the sweating threshold, but comparably and linearly reduces the vasoconstriction and shivering thresholds. Anesthesiology1997; 87: 835-41. 


\section{ORIGINAL ARTICLE}

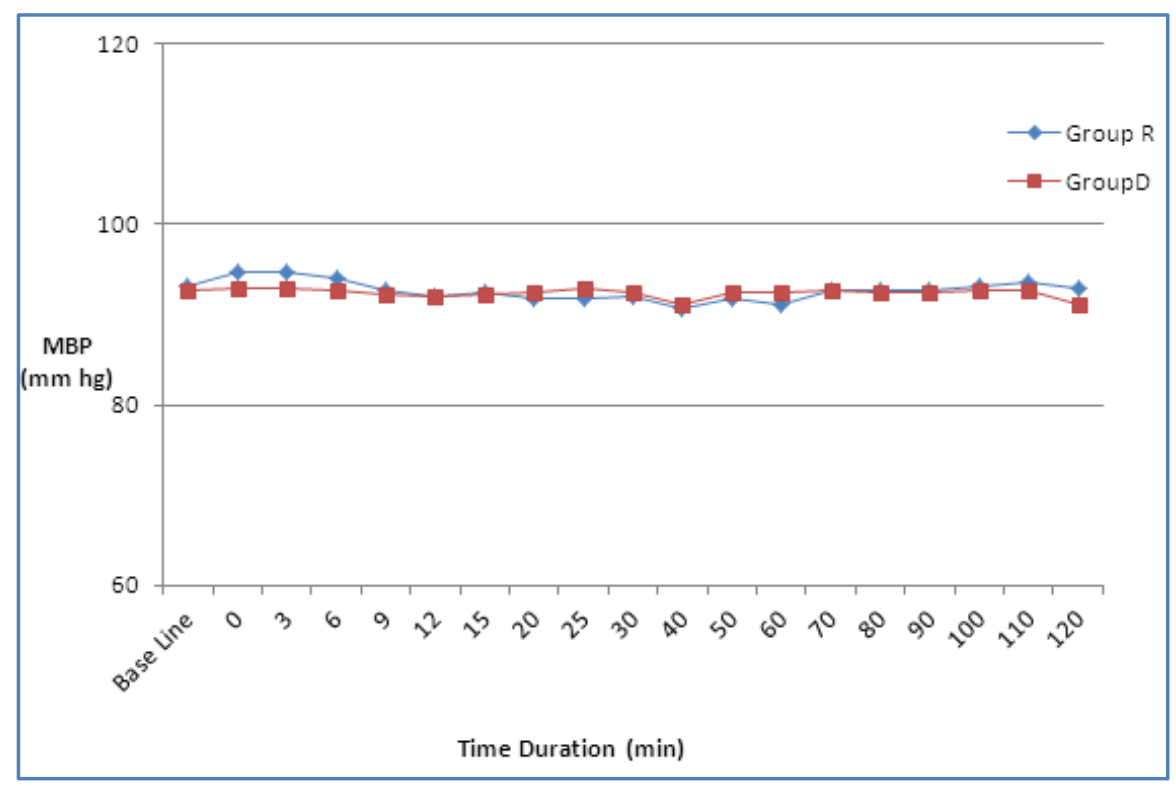

Fig. 1: Comparison of Mean BP ( $\mathrm{mmHg}$ ) between two study groups

Group R - Ropivacaine + Normal saline, Group D - Ropivacaine + Dexmedetomidine

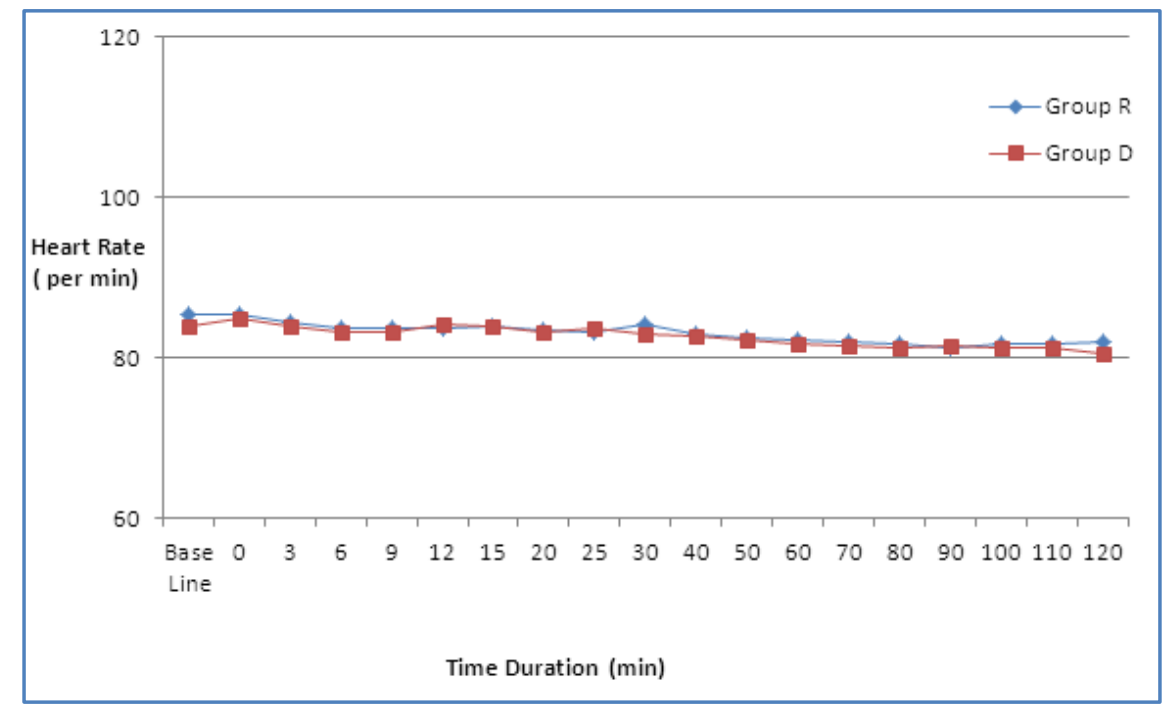

Fig. 2: Comparison of heart rate ( per minute) between the two study groups

Group R - Ropivacaine + Normal saline, Group D - Ropivacaine + Dexmedetomidine 


\begin{tabular}{|l|c|c|c|}
\hline Patient Characteristics & $\begin{array}{c}\text { Group R (59) } \\
\text { Mean } \pm \text { SD }\end{array}$ & $\begin{array}{c}\text { Group D (59) } \\
\text { Mean } \pm \text { SD }\end{array}$ & P Value \\
\hline Age (Yrs) & $45.59 \pm 8.34$ & $44.23 \pm 7.70$ & 0.36 \\
\hline Weight (Kg) & $51.06 \pm 4.34$ & $49.91 \pm 5.18$ & 0.10 \\
\hline Height (cm) & $152.06 \pm 8.08$ & $151.61 \pm 7.41$ & 0.37 \\
\hline BMI & $21.99 \pm 2.45$ & $21.66 \pm 2.26$ & 0.355 \\
\hline ASA Grade I/II & $24 / 35$ & $29 / 30$ & 0.35 \\
\hline Duration of Surgery & $114.74 \pm 15.60$ & $118.16 \pm 17.86$ & 0.68 \\
\hline
\end{tabular}

Table 1: Demographic characteristics of patients

${ }^{*} \mathrm{P}<0.05$-interaction is found to be significant between the groups.

†Group R-Ropivacaine+Normal saline, Group D-Ropivacaine+Dexmedetomidine, BMI-Body Mass Index, ASA-American Society of Anesthesiologists.

\begin{tabular}{|l|c|c|c|}
\hline \multicolumn{1}{|c|}{ Block Characteristics } & $\begin{array}{c}\text { Group R (59) } \\
\text { Mean } \pm \text { SD }\end{array}$ & $\begin{array}{c}\text { Group D (59) } \\
\text { Mean } \pm \text { SD }\end{array}$ & P value \\
\hline Onset of sensory block upto T10 (min) & $3.96 \pm 0.64$ & $4.03 \pm 0.69$ & 0.58 \\
\hline Onset of sensory block upto T8 (min) & $7.44 \pm 0.87$ & $7.35 \pm 0.86$ & 0.59 \\
\hline Onset of sensory block upto T6 (min) & $13.76 \pm 1.89$ & $13.55 \pm 1.85$ & 0.21 \\
\hline $\begin{array}{l}\text { Time of two segment regression from } \\
\text { highest sensory block level (min) }\end{array}$ & $117.00 \pm 15.65$ & $172.37 \pm 18.97$ & $<0.001$ \\
\hline Time of regression to S2 level (min) & $221.35 \pm 22.70$ & $297.71 \pm 34.11$ & $<0.001$ \\
\hline $\begin{array}{l}\text { Time to achievement of } \\
\text { maximum motor blockade (min) }\end{array}$ & $5.46 \pm 0.91$ & $5.54 \pm 0.85$ & 0.60 \\
\hline Total duration of motor blockade (min) & $229.37 \pm 28.74$ & $258.55 \pm 30.46$ & $<0.001$ \\
\hline
\end{tabular}

Table 2: Block Characteristics of patients

${ }^{*} \mathrm{P}<0.05$-interaction is found to be significant between the groups.

†Group R-Ropivacaine+Normal saline, Group D-Ropivacaine+Dexmedetomidine

\begin{tabular}{|l|c|c|c|}
\hline & $\begin{array}{c}\text { Group R (59) } \\
\text { Mean } \pm \text { SD }\end{array}$ & $\begin{array}{c}\text { Group D (59) } \\
\text { Mean } \pm \text { SD }\end{array}$ & P value \\
\hline Time of rescue analgesia ( min) & $174.77 \pm 22.31$ & $270.00 \pm 38.75$ & $<0.001$ \\
\hline Highest pain score on VAS Scale & $7.03 \pm 0.78$ & $4.42 \pm 0.69$ & $<0.001$ \\
\hline $\begin{array}{l}\text { Total number of analgesic injections } \\
\text { given in 1st 24 hours }\end{array}$ & $4.25 \pm 0.75$ & $2.89 \pm 0.66$ & $<0.001$ \\
\hline $\begin{array}{l}\text { Total dose of analgesic consumed } \\
\text { in 1st 24 hours (mg) }\end{array}$ & $421.86 \pm 80.03$ & $283.89 \pm 64.32$ & $<0.001$ \\
\hline \begin{tabular}{l} 
Table 3: Comparison of Postoperative analgesia between the two study groups \\
\hline
\end{tabular}
\end{tabular}

${ }^{*} \mathrm{P}<0.05$-interaction is found to be significant between the groups.

†Group R-Ropivacaine+Normal saline, Group D-Ropivacaine+Dexmedetomidine 


\section{AUTHORS:}

1. Nitish Kumar Parmar

2. Geeta Bhandari

3. K. S. Shahi

4. Gyan Chand

5. Dolly Rani

6. Garima Sharma

7. Santhosh Kumar

\section{PARTICULARS OF CONTRIBUTORS:}

1. Assistant Professor, Department of Anaesthesiology, Government Medical College, Haldwani.

2. Professor, Department of Anaesthesiology, Government Medical College, Haldwani.

3. Professor, Department of Surgery, Government Medical College, Haldwani.

4. Associate Professor, Department of Anaesthesiology, Government Medical College, Haldwani.

5. PG Student, Department of Anaesthesiology, Government Medical College, Haldwani.
6. PG Student, Department of Obstetrics and Gynaecology, Government Medical College, Haldwani.

7. PG Student, Department of Anaesthesiology, Government Medical College, Haldwani.

\section{NAME ADDRESS EMAIL ID OF THE CORRESPONDING AUTHOR:}

Dr. Nitish Kumar Parmar,

Room No. 27, SR Hostel,

Government Medical College,

Haldwani, Nainital.

Uttarakhand - 263139.

E-mail: nitishthebest@gmail.com

Date of Submission: 24/02/2014.

Date of Peer Review: 25/02/2014.

Date of Acceptance: 03/03/2014.

Date of Publishing: 14/03/2014. 